\title{
Effects of recreational use impacts on hiking experiences in natural areas
}

\author{
Natasha A. Lynn, Robert D. Brown \\ School of Environmental Design and Rural Development, University of Guelph, \\ Guelph, Ont., Canada N1G 2WI
}

NOTICE: This is the authors' version of a work that was accepted for publication in LANDSCAPE AND URBAN PLANNING. Changes resulting from the publishing process, such as peer review, editing, corrections, structural formatting, and other quality control mechanisms, may not be reflected in this document. Changes may have been made to this work since it was submitted for publication. A definitive version was subsequently published in LANDSCAPE AND URBAN PLANNING, VOLUME 64, 2003, PAGES 77-87, PII: S0169-2046(02)00202-5. If you refer to this work please cite the published version. 


\begin{abstract}
This study investigated the relationship between recreational use impacts and hiking experiences in natural areas. The effects of trail erosion, extension and widening, muddiness, tree and plant damage, fire rings, and litter were related to four dimensions of recreational experiencessolitude, remoteness, naturalness, and artifactualism. Recreational use impacts were found to have a negative effect on hiking experiences in natural areas. Litter, tree and plant damage, and fire rings had the greatest effect on hiking experience indicators; trail extension and widening and trail erosion had a moderate effect; and muddiness had a minimal effect on experience. Information generated through this study should assist in appropriate planning, design, and management of natural areas to maintain ecological integrity and to provide for quality hiking experiences.
\end{abstract}




\section{Introduction}

There has been a large increase in the recreational use of natural areas over the past few decades. In the United States, total wilderness recreation has increased 10-fold in the past 40 years (Cole and Landres, 1996). The fastest growing recreational activities are associated with trail use (Cordell et al., 1995) and many natural areas provide opportunities for outdoor recreation along trails. Most outdoor recreational activities, however, can adversely affect the natural environment, and the increasing popularity of outdoor recreation has inevitably resulted in greater and more widespread ecological impacts on natural ecosystems (Green, 1998; Sun and Walsh, 1998; Wilson and Seney, 1994). The increasing intensity of the development and use of trails has resulted in various localized changes within natural areas. Trail impacts, including all physical, ecological, and aesthetic effects resulting from the construction and use of trails, are considered to be one of the most prominent recreational use impacts in natural areas (Symmonds et al., 2000; Leung and Marion, 1996). The most common forms of recreational use impacts on trails include soil erosion, muddiness, trail extension and widening, vegetation damage, litter, and fire rings (Marion et al., 1993; Hendee et al., 1990). While some degree of impact might be acceptable, the integrity of natural ecosystems should not be compromised by recreational activities, and the evidence of the impacts should be minimal (Hendee et al., 1990).

One of the most important goals of outdoor recreation management is to provide opportunities for quality recreation experiences (Manfredo et al., 1983). Research on recreational experiences in natural areas has predominantly been focused on the wilderness experience (Kliskey, 1998; Patterson et al., 1998; Ribe, 1994; Brown and Haas, 1980). The wilderness experience embodies such aspects as autonomy, spontaneity, solitude, freedom of action, challenge, risk, spiritual values, and aesthetic appreciation (Kliskey, 1998; Ribe, 1994; Brown and Haas, 1980). The wilderness experience as a whole is an abstract and highly subjective concept, and there is no single attribute upon which the wilderness experience is based. However, four perceptual constructs of the wilderness experience have been identified by Kliskey and Kearsley (1993) as solitude, remoteness, naturalness, and artifactualism (absence of human impact).

One of the most serious problems facing managers of recreational resources is the paradox of protecting natural ecosystems while providing for their recreational use (Kuss and Grafe, 1985). As the demand for recreational experiences in natural areas is growing, it has made the pressure of adhering to this dual mandate difficult (Kliskey, 1994; Kearsley, 1990). Although recreational experiences are affected by a variety of setting attributes, including social, managerial, and natural factors, ecological impacts are rated as among the most important (Floyd et al., 1997). Recreational use impacts are usually heavily concentrated on a small percentage of the total natural area along a few popular trails and destinations (Hendee et al., 1990). Due to the fact that the impacts are compounded in areas most frequented by visitors, they threaten to affect the quality of the visitor experience (Manning et al., 1996; Johnson and Vande Kamp, 1996; Martin et al., 1989). As a result of the increasing popularity of trail use, and the impacts resulting from this proliferation, this paper examined the effect of recreational use impacts on hiking experiences in natural areas. 


\section{Methods}

A study was designed to measure the effect of recreational use impacts (trail erosion, extension and widening, muddiness, tree and plant damage, fire rings, and litter) (Marion et al., 1993; Hendee et al., 1990; Cole, 1985), on the hiking experience of individuals (dimensions of solitude, remoteness, naturalness, and artifactualism) (Kliskey and Kearsley, 1993). A selfadministered questionnaire was developed in order to survey visitors using a hiking trail that runs through a natural area about $100 \mathrm{~km}$ west of Toronto, Canada, near the small community of Arkell (see Fig. 1). The primary focus of the instrument was to investigate the relationship between recreational use impacts and the hiking experience. Demographic information was collected on age, gender, education level, and experience of respondents. Each recreational use impact was on a separate page of the questionnaire, with a photographic representation of the impact (Shelby and Harris, 1985), and respondents were asked to rate how that impact affected the quality of the four specific elements of the hiking experience, using a 5-point Likert-type scale that ranged from decreased greatly to increased greatly (see Fig. 2). A subsequent section of the questionnaire asked respondents to identify how their overall level of satisfaction with hiking trails, in general, was affected by each of the experience indicators, and whether they felt that they contributed to recreational use impacts. Satisfaction in a recreation experience is a multidimensional concept comprised of multiple sources of satisfaction including, psychological outcomes, behavior-type variables (e.g. goal attainment) and setting attributes (e.g. facility development and resource impacts) (Herrick and McDonald, 1992). Understanding recreational satisfaction can help managers and planners to understand the types of opportunities visitors are seeking, and to develop services that help enhance those desired experiences (Buchanan, 1983).

The questionnaire was administered to users of the Starkey Hill Interpretive Trail located east of the village of Arkell on the south side of County Road \#37 (Fig. 1). The trailhead is located on the north side of the property, adjacent to a parking lot. This entrance is the only formally marked entry to the site. The Starkey Hill property is 80 ha and was purchased by the Grand River Conservation Authority (GRCA) in 1972 to protect the City of Guelph's municipal ground water supply (GRCA, 1998). The property is at the interface between a recessional moraine and an outwash plain. Consequently, the terrain on the site varies from rugged ridges with potholes to very flat areas. The property consists of 54 ha of forest and wetland habitat, and 26 ha of agricultural use. The most southerly section of the property consists of a mature forest composed predominantly of Sugar Maple (Acer saccharum) and American Beech (Fagus grandifolia) with an understorey of Ironwood (Carpinus caroliniana), Alternate-leaved Dogwood (Cornus alternifolia), Leatherwood (Dirca palustris) and Spicebush (Lindera benzoin). The remaining forested area consists predominantly of a second-growth plantation with small pockets of natural vegetation. The plantation was established in 1972 and consists predominantly of White Pine (Pinus strobus) with some Paper Birch (Betula papyrifera). Much of the landscape surrounding the Starkey property is under intensive agricultural production, and residential development is increasing rapidly as the population of Southern Ontario grows. As forest remnants have become increasingly fragmented in this landscape, the Starkey Hill property represents an important area for hiking and nature interpretation. In 1973, the Guelph Hiking Trail Club established a $4 \mathrm{~km}$ trail through the site, and the GRCA considers the Starkey Hill Trail to be a "near wilderness experience" (GRCA, 1998, p. 16). 


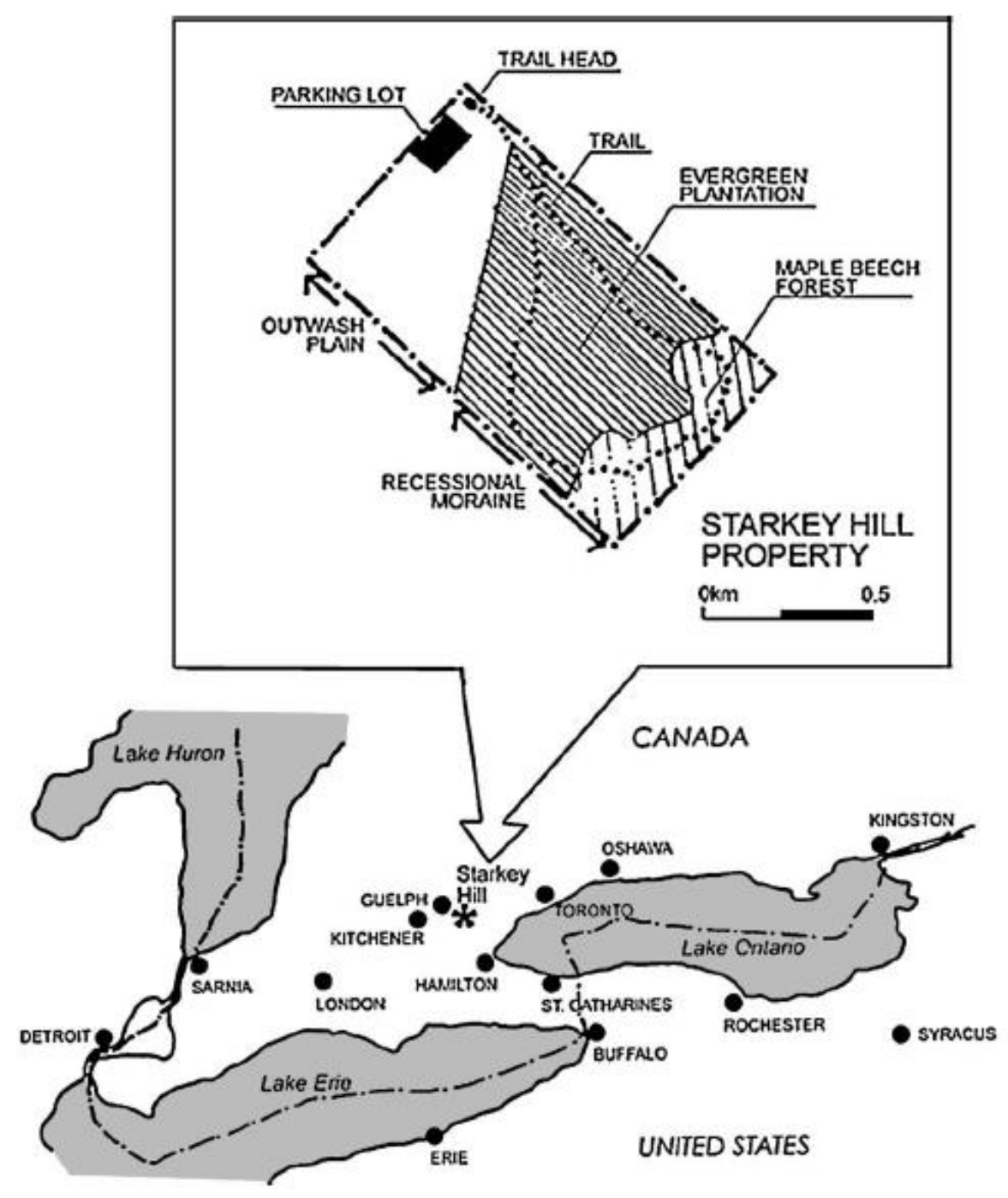

Fig. 1. The Starkey Hill study site is a $4 \mathrm{~km}$ trail located approximately $100 \mathrm{~km}$ west of Toronto, Canada.

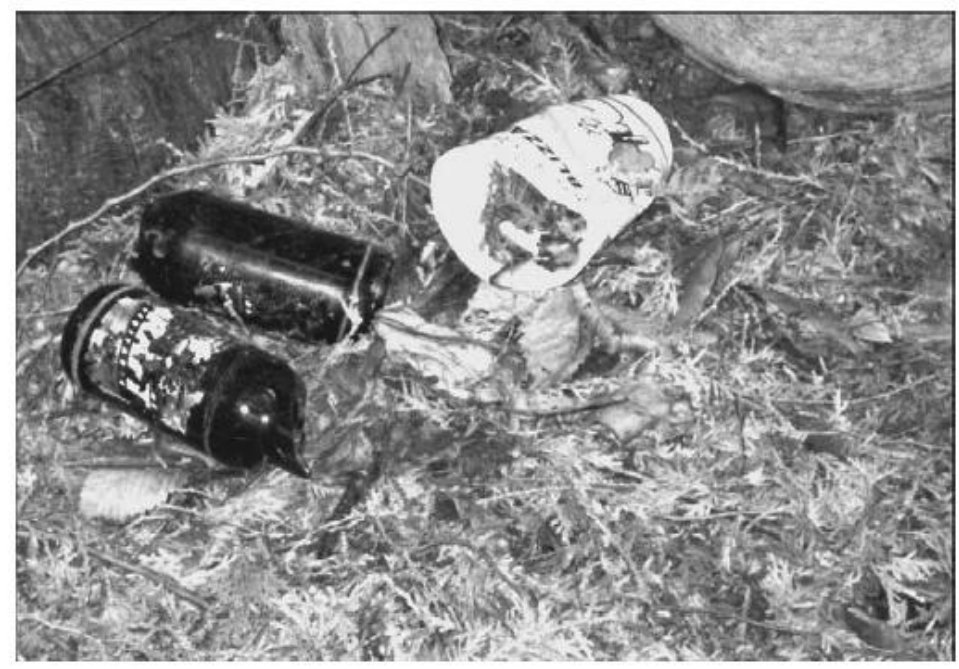

Fig. 2. A typical page from the self-administered questionnaire survey used in the study. 
Visitors to the trail were sampled during May and June 2000. The survey days were stratified to ensure that the interviews were conducted on weekdays, weekends, days within and outside of school holiday periods, days within the season of peak use, and days from off-peak periods (Tourism and Recreation Research Unit, 1983). Within these periods, 8 sample days were chosen using a table of random numbers (Babbie, 1998, p. A32). The survey was conducted on fair weather days. If a sample period occurred on a day of unfavourable weather, an alternate day was chosen. Sampling was focused at the trail head between 11:00 a.m. and 3:00 p.m. when trail use was highest. Hikers were contacted at the trail head as they entered the trail using the next-to-pass sampling method (Tourism and Recreation Research Unit, 1983) to reduce the bias in the choice of respondents. The first hiker to enter was asked to voluntarily complete the questionnaire. Upon the respondent's completion of the questionnaire, the next hiker to pass was approached and asked to complete the questionnaire. The questionnaires were completed before or after their hike according to each respondent's preference. The questionnaire was administered on-site to a sample of 99 hikers. Non-response rates were based on those individuals who did not agree to voluntarily participate. The most common reason for refusal was 'I am in a rush'. The non-response rate was 15\%, and the final usable sample was 82 respondents.

The data resulting from the questionnaire were analyzed through a series of steps. The data that related recreational use impacts to hiking experience indicators were collapsed into two categories ('decreased' and 'not affected or increased') to facilitate the use of McNemar's test for significance (Norusis, 1998; Zar, 1996). McNemar's test (Norusis, 1998; Zar, 1996) was used to test the significance between pairs of dichotomous variables, in this case the difference between each hiking indicator as it related to every other hiking experience indicator, and each recreational use impact as it related to every other recreational use impact. A significance level of 0.05 was used. The data that related to how the experience indicators related to user satisfaction were collapsed into two categories ('minimally to moderately' and 'greatly to severely'). Likewise, the data that related to how users felt that they contributed to recreational use impacts were collapsed into two categories ('not at all to minimally' and 'moderately to severely'). McNemar's test for significance was used to allow for further analysis and to categorize the degree to which the experience indicators related to user satisfaction and the degree that users felt that they contributed to the impacts.

Relationships between any user characteristics or patterns of trail use and the respondents' perceptions of the effect of the recreational use impacts on their hiking experience were also investigated. Two user characteristics (education and gender) and one pattern of trail use (experience based on frequency of general trail use) were identified for study (Floyd et al., 1997; Shin and Jaakson, 1997; Hartig, 1993; Schreyer and Beaulieu, 1986). The $\chi 2$-analysis (Babbie, 1998) was used to test the significance of the relationship between each user characteristic and pattern of trail use, and the respondents' perceptions of the effect of each recreational use impact on each experience indicator. A significance level of 0.05 was used.

\section{Results and discussion}

\subsection{Visitor profile}

Respondents ranged in age from 18 to 83 years, with a mean age of 38. Most respondents were female $(56.1 \%)$ which is unusual in a predominantly male-dominated activity (Shin and 
Jaakson, 1997; Virden and Knopf, 1989). Over 85\% of the sample had completed college or university, and approximately $44 \%$ had acquired a graduate degree, indicating that users were very well educated. The majority of respondents $(45.1 \%)$ used trails frequently (daily to weekly), $33.0 \%$ of respondents used trails moderately (monthly to biweekly), and $17.1 \%$ stated that they participate in trail activities occasionally (a few times per year). Their major reported motivations to visit Starkey Hill were "to enjoy nature" (95.1\%), "for physical exercise" (91.5\%), "to escape the pressures of everyday life" $(65.9 \%)$, "to socialize with friends and family" (59.8\%), "for solitude and tranquility" (59.8\%) and "for personal reflection" (53.7\%). These reported motivations are supported by past motivational research on recreational uses who participate in activities in natural areas (Walker et al., 1998; Ribe, 1994; Virden and Knopf, 1989; Brown and Haas, 1980).

\subsection{Categorization of the experience indicators}

The relationship between the hiking experience indicators and the recreational use impacts was investigated by categorizing the experience indicators to determine which hiking experience indicators were most affected by the recreational use impacts. Histograms of data collapsed into three categories (decreased, not affected, increased) were used to determine the magnitude that each impact, in turn, had on the four hiking experience indicators. For example, the impact 'trail erosion' affected the hiking experience indicators to different levels, with 'solitude' being the least affected (see 'decreased" column), and 'artifactualism' being the most affected (see Fig. 3). McNemar's test for significance indicated whether each impact affected the hiking experience indicators differently, or if the difference was marginal and could be considered the same from a statistical point of view. For example, trail erosion affected solitude differently from every other indicator, but affected naturalness and remoteness the same (i.e. no significant difference between the effect of trail erosion on these two indicators was determined) (see Table 1). These two measures allowed both the determination of the relative amount that each indicator was affected by each impact (i.e. most affected, moderately affected, or least affected), and for the effects to be categorized. In the above example, the categories determined were that trail erosion: most affected artifactualism, moderately affected naturalness and remoteness, and least affected solitude. The results of the individual tests have been amalgamated in Table 2. All experience indicators were most affected by litter, while every indicator except artifactualism was least affected by muddiness.

\subsection{Other analyses}

Education, gender, and experience are commonly related to perceptions of environmental impacts (Shin and Jaakson, 1997; Roggenbuck et al., 1993; Hartig, 1993). A _2-test indicated that gender, experience, and education had minimal effect on the respondents' perceptions of the recreational use impacts on the experience indicators. Respondents were asked the level to which they thought they were contributing to recreational use impacts on the trails that they use. The majority of respondents felt they contributed minimally or not at all to litter $(90.2 \%)$ and fire rings (86.6\%) (Fig. 4). Significantly fewer (see Table 3) felt that they contributed minimally or not at all to tree and plant damage (75.6\%), and fewer yet felt that they contributed minimally or not at all to muddiness $(56.1 \%)$, trail extension (52.4\%) and trail erosion (51.2\%). 
Respondents were also asked to indicate the level of contribution of the experience indicators to their level of overall trail-use satisfaction in general. Results indicated that they felt that naturalness contributed most to their overall experience, with $78.0 \%$ stating that it contributed greatly to extremely (Fig. 5). Significantly fewer (see Table 4) felt that artifactualism $(69.5 \%)$, solitude $(63.4 \%)$ and remoteness $(59.8 \%)$ contributed greatly to extremely to their overall satisfaction.
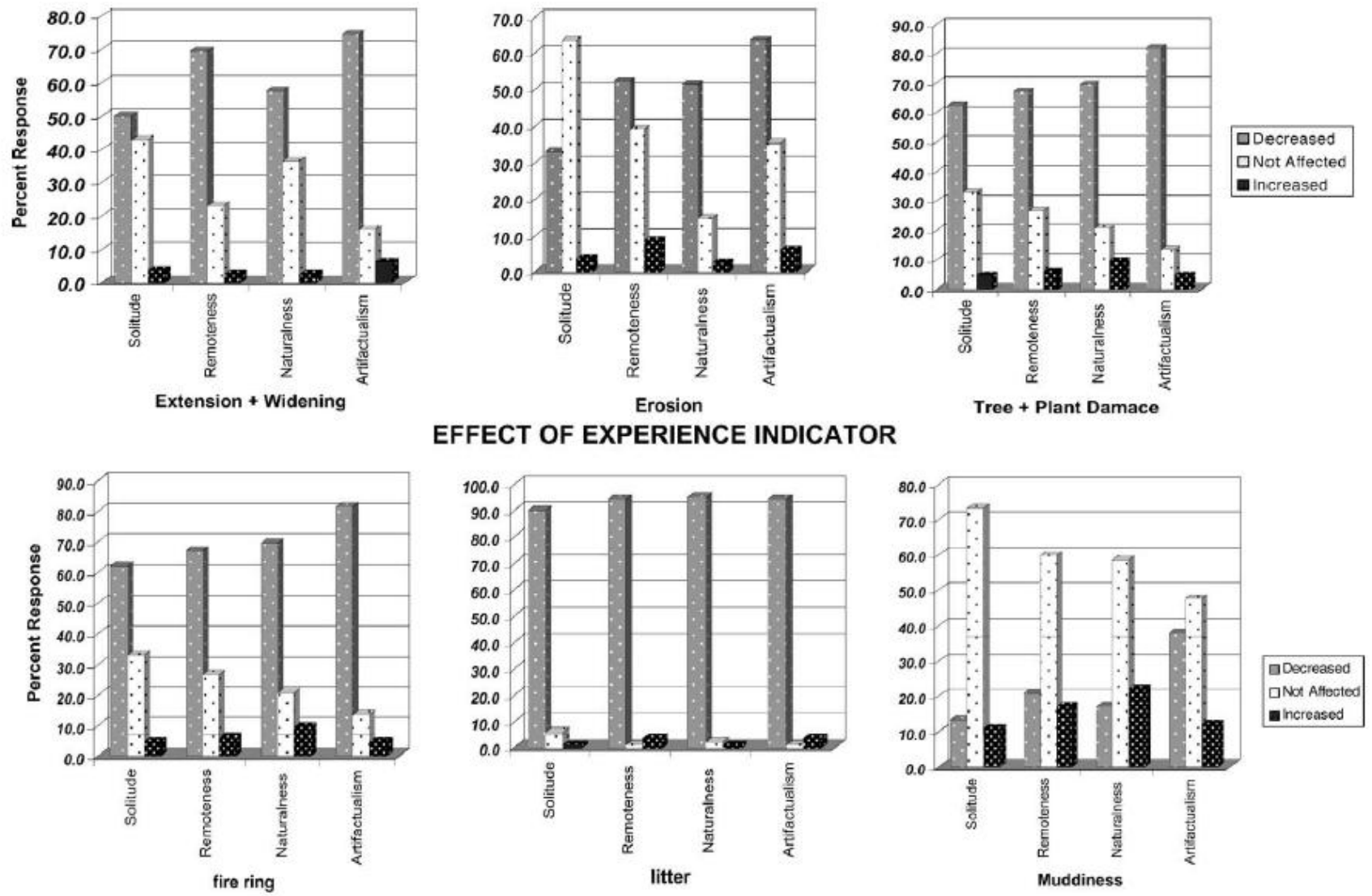

\section{EFFECT ON EXPERIENCE INDICATOR}

Fig. 3. Frequency of response for the effect of each recreational use impact on hiking experience indicators. For example, over $90 \%$ of respondents said that litter decreased their feeling of solitude, while only a small percentage said that their feeling of solitude was not affected or was increased by litter. 
Table 1

Results of test of significance for each of the experience indicators as they were affected by each of the recreational use impacts

\begin{tabular}{|c|c|}
\hline Paired experience indicators & $P$-value \\
\hline \multicolumn{2}{|c|}{ McNemar's test for trail extension and widening } \\
\hline Solitude and remoteness & $<0.001$ \\
\hline Solitude and artifactualism & $<0.001$ \\
\hline Naturalness and artifactualism & 0.004 \\
\hline Remoteness and naturalness & 0.027 \\
\hline Solitude and naturalness & 0.238 \\
\hline Remoteness and artifactualism & 0.607 \\
\hline \multicolumn{2}{|l|}{ McNemar's test results for fire rings } \\
\hline Solitude and artifactualism & 0.002 \\
\hline Remoteness and artifactualism & 0.008 \\
\hline Naturalness and artifactualism & 0.021 \\
\hline Solitude and naturalness & 0.180 \\
\hline Solitude and remoteness & 0.454 \\
\hline Remoteness and naturalness & 0.727 \\
\hline \multicolumn{2}{|c|}{ McNemar's test results for trail erosion } \\
\hline Solitude and remoteness & $<0.001$ \\
\hline Solitude and artifactualism & $<0.001$ \\
\hline Solitude and naturalness & 0.004 \\
\hline Naturalness and artifactualism & 0.031 \\
\hline Remoteness and artifactualism & 0.049 \\
\hline Remoteness and naturalness & 1.000 \\
\hline \multicolumn{2}{|l|}{ McNemar's test results for litter } \\
\hline Solitude and naturalness & 0.375 \\
\hline Solitude and remoteness & 0.688 \\
\hline Solitude and artifactualism & 0.688 \\
\hline Remoteness and naturalness & 1.000 \\
\hline Remoteness and artifactualism & 1.000 \\
\hline Naturalness and artifactualism & 1.000 \\
\hline \multicolumn{2}{|c|}{ McNemar's test results for tree and plant damage } \\
\hline Solitude and artifactualism & 0.049 \\
\hline Solitude and remoteness & 0.057 \\
\hline Solitude and naturalness & 0.092 \\
\hline Naturalness and artifactualism & 0.754 \\
\hline Remoteness and naturalness & 1.000 \\
\hline Remoteness and artifactualism & 1.000 \\
\hline \multicolumn{2}{|c|}{ McNemar's test results for muddiness } \\
\hline Solitude and artifactualism & 0.000 \\
\hline Naturalness and artifactualism & $<0.001$ \\
\hline Remoteness and artifactualism & 0.003 \\
\hline Solitude and remoteness & 0.146 \\
\hline Remoteness and naturalness & 0.581 \\
\hline Solitude and naturalness & 0.581 \\
\hline
\end{tabular}

Italic values indicate significant differences $(P<0.05)$ which were used to categorize the experience indicators. $P$-value $<0.05$ indicates significance. 


\subsection{The impacts}

The results of this study indicate a strong negative relationship between recreational use impacts and hiking experience indicators. These findings support the assumptions made by Johnson and Vande Kamp (1996), Hendee et al. (1990) and Martin et al. (1989) that recreational use impacts might have the potential to negatively affect the quality of visitor experiences. Litter had the greatest effect on all the experience indicators. Past studies have similarly found that visitors consider litter to be the most objectionable recreational use impact in natural areas (Floyd et al., 1997; Shafer and Hammit, 1995; Roggenbuck et al., 1993). Fire rings had a large negative effect on all of the hiking experience indicators in this study, which is counter to the results of many other studies (Shelby and Shindler, 1992; Martin et al., 1989; Shelby et al., 1988). However, much of the earlier work was conducted in backcountry areas where the occurrence of fire rings is often associated with the presence of campsites, an important part of traditional wilderness experiences (Shelby and Shindler, 1992). As the Starkey Hill Trail is a day-use site where fires are not allowed, the presence of fire rings are more likely to be perceived as unacceptable.

Plant damage also had a large effect on all the hiking experience indicators. These results are supported by past research which suggested that visitors are very concerned about vegetation damaged by users (Shafer and Hammit, 1995; Roggenbuck et al., 1993). Trail extension and widening had a large effect on all experience indicators with the exception of naturalness. Little research has been done on visitors' perceptions

Table 2

Categorization of hiking experience indicators indicating the degree to which each was affected by trail use impacts

\begin{tabular}{llll}
\hline Impact & \multicolumn{2}{l}{ Degree the hiking experience indicator was affected } & Least affected \\
\cline { 2 - 4 } & Most affected & Moderately affected & Solitude \\
\hline Extension and widening & Artifactualism, remoteness & Naturalness, solitude & Remoteness, naturalness \\
Trail erosion & Artifactualism & Solitude & Naturalness, remoteness, \\
Tree and plant damage & Artifactualism, remoteness, naturalness & Artifactualism & solitude \\
Muddiness & & Naturalness, remoteness, solitude & \\
Fire rings & Artifactualism & & \\
Litter & Artifactualism, remoteness, naturalness, & & \\
& solitude &
\end{tabular}

of trail extension and widening, although Symmonds et al. (2000) examined the effect of various impacts on the mountain biking experience and found that wide trails detracted slightly from the quality of the biking experience. The finding that trail extension and widening had only a moderate effect on naturalness might be attributed to the fact that the photographic representation in our survey depicted a less-traveled trail meandering off the main trail. Some respondents might have felt that this form of trail extension and widening offered an escape into more natural surroundings.

Trail erosion had a moderate effect on all the experience indicators. Previous research has suggested that visitors are concerned about erosion, especially when it occurs along hiking trails and stream banks (Noe et al., 1997; Floyd et al., 1997). Muddiness had a minimal effect on all of the experience indicators. Although little research has been done on users' perceptions of muddiness in relation to hiking, Symmonds et al. (2000) found that conditions related to improper or poor trail drainage detracted slightly from the quality of the biking experience. 
Although muddiness occurs when a trail surface is converted to a soft muddy condition as a result of continual trampling (Pratt, 1976; Roemer, 1975), it is often perceived as a naturally occurring impact strictly associated with rainfall. Therefore, muddiness may not be perceived as a human impact and thereby have little to no effect on the experience indicators.

\subsection{Effects of user characteristics}

The results of this study suggested there was essentially no relationship between gender, experience, education, and the respondents' perceptions of the recreational use impacts on the hiking experience indicators. These findings support those of Schreyer and Beaulieu (1986), who stated that persons with varying levels of experience and commitment do not appear to differ significantly in the types of attributes they identify as important in selecting wildland recreation environments.

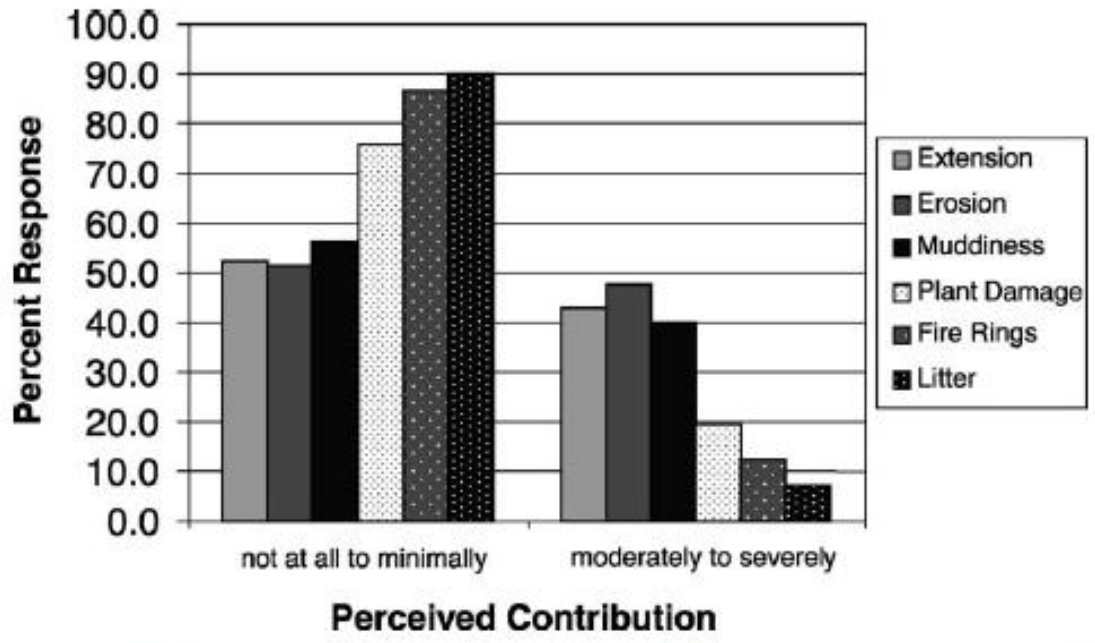

Fig. 4. Frequency of response of hikers' perceived contribution to recreational use impacts. For example, about half of the respondents felt that they contributed "not at all to minimally" to extension, erosion, and muddiness.

Table 3

Results of test of significance for respondents' perceived contribution to recreational use impacts

\begin{tabular}{lc}
\hline Paired impacts & $P$-value \\
\hline Fire rings and trail extension & $<0.001$ \\
Trail extension and plant damage & $<0.001$ \\
Trail extension and litter & $<0.001$ \\
Trail erosion and fire rings & $<0.001$ \\
Trail erosion and litter & $<0.001$ \\
Fire rings and muddiness & $<0.001$ \\
Muddiness and plant damage & $<0.001$ \\
Muddiness and litter & $<0.001$ \\
Trail erosion and plant damage & $<0.001$ \\
Plant damage and litter & 0.021 \\
Fire rings and plant damage & 0.180 \\
Fire rings and litter & 0.219 \\
Trail erosion and muddiness & 0.227 \\
Trail erosion and trail extension & 0.481 \\
Trail extension and muddiness & 0.824
\end{tabular}

Italic values indicate significant differences $(P<0.05)$ which were used to categorize the data.
Table 4

Results of test of significance for trail users' responses relating the experience indicators to overall satisfaction levels

\begin{tabular}{lr}
\hline Paired indicators & $P$-value \\
\hline Solitude and naturalness & $<0.001$ \\
Remoteness and naturalness & $<0.001$ \\
Naturalness and artifactualism & 0.002 \\
Remoteness and artifactualism & 0.454 \\
Solitude and remoteness & 0.581 \\
Solitude and artifactualism & 1.000
\end{tabular}

Italic values indicate significant differences $(P<0.05)$ which were used to categorize the responses. 


\subsection{User contribution to recreational use impacts}

Most respondents felt that they had not contributed to or had a minimal contribution to litter, tree and plant damage, and fire rings. Interestingly, these impacts were regarded as having the most significant effect on the hiking experience indicators. On the other hand, almost half of the respondents felt that they contributed moderately to severely to trail erosion, trail extension and widening, and muddiness. These impacts had a moderate to minimal effect on the hiking experience indicators. This suggests that users do not contribute to impacts that would be most likely to degrade their own recreational experience.

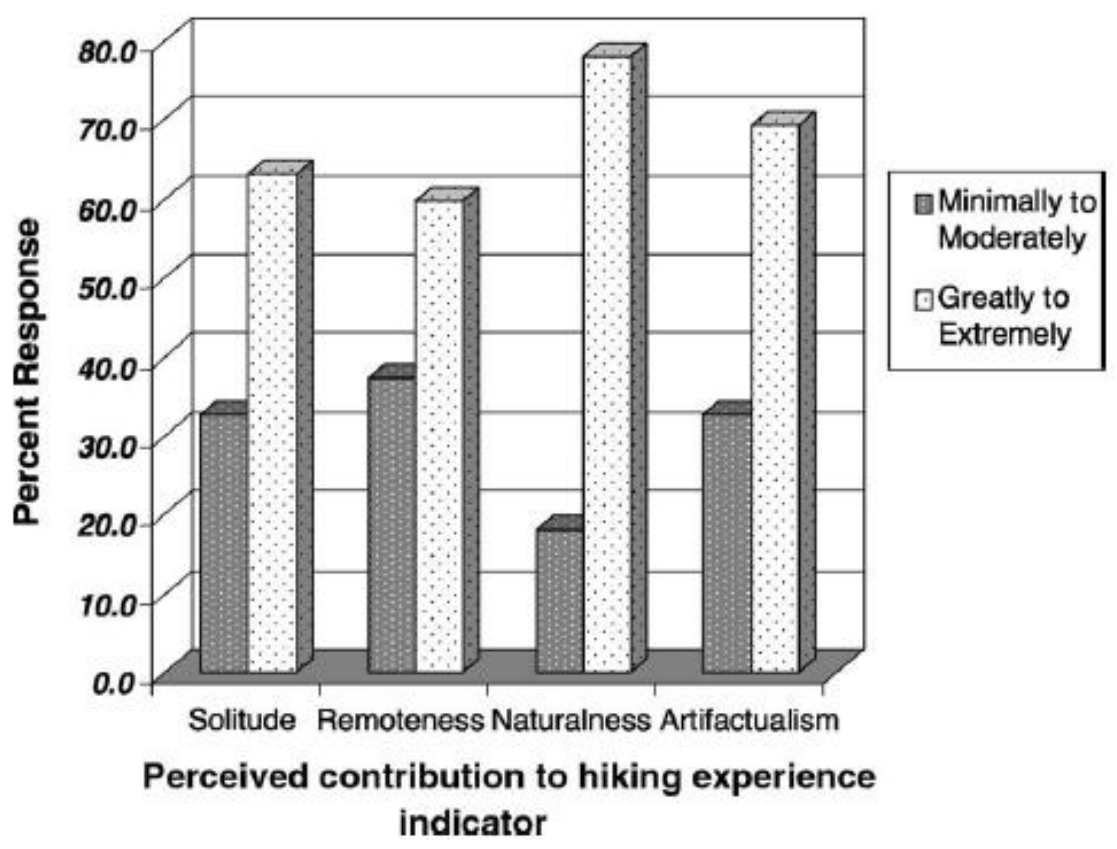

Fig. 5. Frequency of response for the contribution of experience indicators to overall satisfaction. For example, almost $80 \%$ of respondents felt that naturalness contributed "greatly to extremely" to their quality of hiking experience.

\subsection{User satisfaction}

The results of this study indicated that all of the experience dimensions contributed greatly to the respondents' overall satisfaction, although naturalness was perceived to have a significantly greater contribution to overall satisfaction than artifactualism, remoteness, and solitude. These findings are supported by Herrick and McDonald (1992) who suggested that visitors use setting attributes to evaluate their overall satisfaction. The importance of the experience dimensions to overall satisfaction emphasizes the fact that visitors specifically seek experiences relating to artifactualism, naturalness, remoteness and solitude when hiking in natural areas. It also provides further support for using these perceptual constructs as operationalized indicators for recreational experiences in natural areas. 


\section{Conclusion}

Providing quality recreational experiences can be enhanced through a better understanding of the users. Managers can facilitate the ability of users to realize their desired experiences by ensuring that the settings that contribute greatly to their experiences are made available (Manfredo et al., 1983; Brown and Haas, 1980). This study identified specific setting attributes and experience preferences of users by assessing the effect of recreational use impacts on hiking experiences in natural areas. The results clearly indicated that recreational use impacts negatively affected hiking experiences in natural areas. More specifically, it was suggested that litter, tree and plant damage, fire rings, trail extension and widening and trail erosion had a negative effect on perceptions of artifactualism, remoteness, naturalness, and to a lesser degree, solitude. Of the recreational use impacts studied, only muddiness had a minimal effect on all the experience indicators. It was also concluded that all of the experience indicators contributed greatly to the overall satisfaction of hikers. Therefore, in order to protect the quality of hiking experiences, management techniques should be implemented to reduce the amount of litter, tree and plant damage, fire rings, trail extension and widening, and erosion.

One of the main challenges of the planning, design, and management of natural areas is making decisions that will produce the best quality user experience, while protecting the ecological integrity of the resource base (Shin and Jaakson, 1997). This study has identified recreational use impacts that affect hiking experience, but many of the impacts affect ecological integrity as well. Information generated through this study should assist in appropriate planning, design and management of natural areas both to maintain ecological integrity and to provide for quality hiking experiences. 


\section{References}

Babbie, E., 1998. The Practice of Social Research, 8th ed. Wadsworth Publishing Company, 112 pp.

Brown, P.J., Haas, G.E., 1980. Wilderness recreation experiences: the Rawah case. J. Leisure Res. 12, 229-241.

Buchanan, T., 1983. Toward an understanding of variability in satisfactions within activities. J. Leisure Res. 15, 39-51.

Cole, D.N., 1985. Management of ecological impacts in wilderness areas in the United States. In: Bayfield, N.G., Barrow, G.C. (Eds.), Proceedings of the Conference of Recreational Research Group on The Ecological Impacts of Outdoor Recreation in Mountain Areas in Europe and North America, Cumbria, pp. 138-153.

Cole, D.N., Landres, P.B., 1996. Threats to wilderness ecosystems: impacts and research needs. Ecol. Appl. 6, 168-184.

Cordell, H.K., Lewis, B., McDonald, B.L., 1995. Long-term outdoor recreation participation trends. In: Thompson, J., Gartner, B, Lime, D.W., Sames, W.M. (Eds.), Proceedings of the Fourth International Outdoor Recreation Tourism Trends Symposium and the 1995 National Recreation Resource Planning Conference, University of Minnesota, pp. 35-38.

Floyd, M.F., Jang, H., Noe, F.P., 1997. The relationship between environmental concern and acceptability of environmental impacts among visitors to two US National Park settings. J. Environ. Manage. 51, 312-391.

Grand River Conservation Authority (GRCA), 1998. Starkey Hill Management Plan, unpublished data, $19 \mathrm{pp}$.

Green, D.M., 1998. Recreational impacts on erosion and runoff in a central Arizona riparian area. J. Soil Water Conserv. 53, 38-42.

Hartig, T., 1993. Nature experience in transactional perspective. Landscape Urban Plann. 25, 1736.

Hendee, J.C., Stankey, G.H., Lucas, R., 1990. Wilderness Management, 2nd ed. North American Press, Golden, CO.

Herrick, T.A., McDonald, C.D., 1992. Factors affecting overall satisfaction with the river recreation experience. Environ. Manage. 16, 243-247.

Johnson, D.R., Vande Kamp, M.E.V., 1996. Extent and control of resource damage due to noncompliant visitor behavior: a case study from the US National Parks. Nat. Areas J. 16, 134141. 
Kearsley, G.W., 1990. Tourism development and users' perception of wilderness in southern New Zealand. Austr. Geogr. 21, 127-140.

Kliskey, A.D., 1998. Linking the wilderness perception mapping concept to the recreation opportunity spectrum. Environ. Manage. 22, 79-88.

Kliskey, A.D., 1994. A comparative analysis of approaches to wilderness perception mapping. J. Environ. Manage. 41, 199-236.

Kliskey, A.D., Kearsley, G.W., 1993. Mapping multiple perceptions of wilderness in southern New Zealand. Appl. Geogr. 13, 203- 223.

Kuss, R.F., Grafe, A.R., 1985. Effects of recreation trampling on natural area vegetation. J. Leisure Res. 17, 165-183.

Leung, Y., Marion, J.L., 1996. Trail degradation as influenced by environmental factors: a stateof-the-knowledge review. J. Soil Water Conserv. 51, 130-136.

Manfredo, M.J., Driver, B.L., Brown, P.J., 1983. A test of concepts inherent in experience based management of outdoor recreation areas. J. Leisure Res. 15, 263-283.

Manning, R.E., Ballinger, N.L., Marion, J., Roggenbuck, J., 1996. Recreation management in natural areas: problems and practices, status and trends. Nat. Areas J. 16, 142-146.

Martin, S.R., McCool, S.F., Lucas, R.C., 1989. Wilderness campsite impacts: do managers and visitors see them the same? Environ. Manage. 13, 623-629.

Marion, J.F., Roggenbuck, J.W., Manning, R.E., 1993. Problems and practices in backcountry recreation management: a survey of National Park Service Managers. US Department of the Interior, NPS, Natural Resources Office, Colorado, 43 pp.

Noe, F.P., Hammit, W.E., Bixler, R.D., 1997. Park user perceptions of resource and use impacts under varied situations in three national parks. J. Environ. Manage. 49, 323-336.

Norusis, M.J., 1998. SPSS 8.0 Guide to Data Analysis. Prentice-Hall, New Jersey. 563pp.

Patterson, M.E., Watson, A.E., Williams, D.R., Roggenbuck, J.R., 1998. An hermeneutic approach to studying the nature of wilderness experiences. J. Leisure Res. 30, 423-452.

Pratt, R., 1976. The Ecological Impacts of Recreation in Natural Environments. York University, York, $140 \mathrm{pp}$.

Ribe, R.G., 1994. Scenic beauty perceptions along the ROS. J. Environ. Manage. 42, 199-221. 
Roemer, H.L., 1975. Ecological Impact of Recreational Use In the Berg Lake Area, Mt. Robson Provincial Park. Project No. 74R1. Department of Recreation and Conservation. Victoria, BC, 98 pp.

Roggenbuck, J.W., Williams, D.R., Watson, A.E., 1993. Defining acceptable conditions in wilderness. Environ. Manage. 17, 187- 197.

Schreyer, R., Beaulieu, J.T., 1986. Attribute preferences for wildland recreation setting. J. Leisure Res. 18, 231-247.

Shafer, S.C., Hammit, W.E., 1995. Congruency among experience dimensions, condition indicators, and coping behaviors in wilderness. Leisure Sci. 17, 263-279.

Shelby, B., Shindler, B., 1992. Interest group standards for ecological impacts at wilderness campsites. Leisure Sci. 14, 17-27.

Shelby, B., Vaske, J.J., Harris, R., 1988. User standards for ecological impacts at wilderness campsites. J. Leisure Res. 20, 245-256.

Shelby, B., Harris, R., 1985. Comparing methods of determining visitor evaluations of ecological impacts: site visits, photographs, and written descriptions. J. Leisure Res. 17, 57-67.

Shin, S.W., Jaakson, R., 1997. Wilderness quality and visitors' wilderness attitudes: management implications. Environ. Manage. 21, 225-232.

Sun, D., Walsh, D., 1998. Review of studies on environmental impacts of recreation and tourism in Australia. J. Environ. Manage. 53, 323-338.

Symmonds, M.C., Hammitt, W.E., Quisenberry, V.L., 2000. Managing recreational trail environments for mountain bike user preference. Environ. Manage. 25, 549-564.

Tourism and Recreation Research Unit (TRRU), 1983. Recreation Site Survey Manual. E. \& F.N. Spon Ltd., London. 146 pp.

Virden, R.J., Knopf, R.C., 1989. Activities, experiences and environmental settings: a case study of recreation opportunity spectrum relationships. Leisure Sci. 11, 159-176.

Walker, G.J., Hull IV, R.B., Roggenbuck, J.W., 1998. On-site optimal experiences and their relationship to off-site benefits. J. Leisure Res. 30, 453-471.

Wilson, J.P., Seney, J.P., 1994. Erosional impact of hikers, horses, motorcycles, and off-road bicycles on mountain trails in Montana. Mountain Res. Dev. 14, 77-88.

Zar, J.H., 1996. Biostatistical Analysis, 3rd ed. Prentice-Hall, New Jersey, 662 pp. 